\title{
Effect of Differentiated Instruction and 5E Learning Cycle on Academic Achievement and Self-efficacy of Students in Physics Lesson
}

\author{
Riza Salar*, Umit Turgut \\ Department of Science Education, Faculty of Education, Ataturk University, Erzurum, Turkey \\ *Corresponding Author: rizasalar@atauni.edu.tr
}

\section{ABSTRACT}

The learning characteristics of each student are different. Differentiated instruction considers individual differences, as such guides the learning journey rather than seeing these differences as a challenge. The purpose of this research was to compare the effects of differentiated instruction and 5E learning cycle in physics classes on the students' academic achievement and self-efficacy. We used the matching - pre-test/post-test - control group design to address the research questions. We conducted the study in three different schools, performed three experiments, and had three control groups. $16210^{\text {th }}$ grade students participated in the study. We used the "Electricity Prior Knowledge Test," "Electricity Achievement Test," and the "Physics Self-Efficacy Scale" to collect data. SPSS version 20 software was used to analyze the obtained quantitative data. Independent samples t-test was used to determine whether there was a significant difference between the control and experimental group students' level of prior knowledge regarding the subject of electricity. The analysis of covariance was used to determine whether there was a significant difference between the control and experimental group students' course achievements after the implementation. Two-factor mixed-measures ANOVA was used to determine whether the experimental and control group students' pre-test and post-test scores on self-efficacy differed. Based on the results, it can be concluded that differentiated instruction improved the academic achievement of the low- and mid-achieving students. When the self-efficacy scores of the students were analyzed, no significant difference was found between the groups. Based on the results of the research, researchers or teachers who want to use differentiated teaching in their classrooms may be recommended to create level groups in the classroom.

KEY WORDS: differentiated instruction; 5E learning cycle; physics teaching

\section{INTRODUCTION}

I

$\mathrm{n}$ the $21^{\text {st }}$ century, teachers are challenged to determine how best to meet their students' needs while meeting local, state, and national pressures of standardized tests (Ducey, 2011). One 21 $1^{\text {st }}$-century focus in education is to use differentiated instruction as a possible solution to this challenge and to improve the quality of education provided to students (Tomlinson, 2001). Differentiated instruction (DI) is a teaching method in which the teacher changes teaching depending on the academic needs of each student (Pinnell and Fountas, 2007; Levy, 2008). DI requires teachers to combine teaching strategies into new or meaningful combinations to meet each student's different learning needs (Tomlinson, 1999, 2001; Wormeli, 2007). In a differentiated classroom, teachers accept and work with the differences of students instead of trying to ignore student differences (Tomlinson, 1999, 2001). Sternberg and Zhang (2005) argue that the main idea of differentiation is to maximize students' levels and overcome difficulties.

Students are not containers waiting to be filled with knowledge. On the contrary, they build their knowledge and understanding of the world around them. Diversity in students' academic achievements, interests, and previous life experiences can lead to different learning needs. Teachers using DI evaluate students' prior knowledge and skills, and these results can be used as multiple entry points at the beginning of the unit (VanTassel-Baska and Stambaugh, 2005). Teachers must take into account the diversity of students and they have to create the appropriate environment to understand, respect, and respond to this diversity (Tulbure, 2013). Teachers are aware that each student is different from each other and that their differences are remarkable (George, 2005). The teacher designs the teaching according to the student's needs, which are determined by frequent measurements and evaluations (Boushey and Moser, 2006; Cusumano and Mueller, 2007). Without DI, talented students may see school as a place to tolerate and think that learning will take place in out-of-school settings. Some of these students have less interest in lessons. And some of them pose disciplinary issues. Therefore, teachers often overlook these students' talents (George, 2005).

\section{Differentiated Instruction}

Each child has characteristics that determine "what is best for $\mathrm{him} / \mathrm{her}$," what type or frequency of instruction they need to support them, what discipline and guidance are needed, and what is interesting to them (Ducey, 2011). How much benefit 
can a standardized instruction provide to students who are different from each other in terms of multiple features? In this diversity of students, the idea of differentiating instruction with DI has been put forward to maximize the learning of each student from their perspective. Principles of multiple intelligence theory and constructivism are the basis of DI. Researchers have stated that learning environments in which these two theories are applied to increase students' achievement (Lawrence-Brown, 2004; Levy, 2008; Tomlinson, 2009).

DI is a belief system that argues that all students entering the class have the potential to succeed (Roberts-Mahon, 2016). This is not a new phenomenon. It has long been used for gifted and special education students. What is new is the idea that it can be used for all students (Blaz, 2006). Hall (2002) defined DI as a teaching theory based on the idea that teaching techniques should be adapted to the individual and different needs of students. George (2005) stated that without DI, it is almost impossible to create a meaningful learning environment by dealing with various mixtures of ethnic, cultural, and socio-economic factors. Instead of defining DI as a strategy or process, he stated that a teacher should be considered as one of the many tools that can be used to meet the needs of their students.

DI is about student-centered learning. In DI, the teacher creates an effective classroom environment by accepting that students do not always need to know all the answers, but instead are concerned with finding them guided learning activities (Tomlinson, 1999). DI is for all students and heterogeneous groups. It can be said that DI is an approach that supports student learning. It can increase the learning potential of all students when applied in the classroom (Hall et al., 2003; Levy, 2008; Reis et al., 1998; Subban, 2006; Tomlinson, 1999, 2001, 2003; Willis and Mann, 2000). Hall (2002) stated that the goal of DI is to maximize the development and individual success of each student by identifying where each student is located and helping the learning process. In an effective classroom, students are accepted for both their similarities and their differences (Tomlinson, 1999).

In DI, different learning pathways are designed for students with different characteristics (Tomlinson, 2001). Students' prior knowledge, learning pace, cognitive abilities, learning styles, and socio-economic status are different from each other. The teacher differentiates the teaching based on at least one of these parameters. The teacher who accepts that the students are different in terms of prior knowledge, learning pace, cognitive ability, learning style, and socioeconomic status, and who wants to teach accordingly, will ask two questions: (i) What should I differentiate? (ii) How should I differentiate? The answer to the first question corresponds to three items. These are content, process, and product. Content is the learning outcomes to be taught. Tomlinson (2001) defines the content as the knowledge that the teacher wanted to teach students. The process is how the teaching takes place. The methods that the teacher follows while teaching a subject, the materials used, the environment design, and the timing, constitute the process. The product is the item that students show what they have learned (Tomlinson, 2001). In other words, it is the result of learning. A teacher can differentiate content, process, and product, or any combination. "How should I differentiate?" The answer to this question corresponds to teaching strategies that support differentiation. Strategies such as agenda, centers, station, tiered activities, group investigations, and learning contracts are generally used in DI.

\section{Agenda}

The agenda strategy was used in this study. Agenda is a strategy that allows students to be assigned individual tasks appropriate to their levels. In this strategy, each student has an agenda that consists of 2-3 weeks of individual or group tasks. The purpose of the tasks is for the student to complete the missing points and/or provide in-depth knowledge on the subject (Tomlinson, 2001). With agendas, students encounter activities that are suitable to them and their levels. Salar and Turgut (2015) used the agenda strategy in their studies, where they aimed to identify the imperfect knowledge of pre-service physics teachers in optics, energy, force, and motion and then to address these using DI. An example of agenda used in this study is presented in Table 1 .

\section{Purpose of the Research}

If we consider the diversity of students, the cognitive needs of students will also vary. Responding to this diversity may be possible with DI. A differentiated classroom is flexible and student-oriented; students are at the center of learning (Bafile, 2010). Three factors are decisive in a student's education: The student's learning styles, interests, and readiness (Fischer and Rose, 2001). According to Larsen (2004), DI aims to bring the ideas and concepts of the curriculum to the student at a pace and depth suitable for each student's ability. To take students to a higher level of knowledge, it is necessary to know their current level of knowledge. Given the individual differences of the students, their prior knowledge levels will also be different. Especially when we consider a high school level course, students will be expected to come with a lot of knowledge related to that course from their previous education life. If we assume that the new knowledge will be built on the existing, learning will be difficult if the existing knowledge is false or incomplete. Moreover, if we consider a classroom environment where this prior knowledge will be different for each student due to the individual differences of the students, it will be difficult for the teacher to overcome. This is one of the difficulties in teaching physics. There is a lot of prior knowledge that teachers expect students to have learned in their previous learning experiences, especially in mathematics and science. This prior knowledge is a basis for the new knowledge and skills that the teacher will teach. This basis differs for each student. If we think that the learning pace of the students is different from each other in addition to this difference, it will be very difficult for the teacher to plan teaching that will cover all the students. 


\begin{tabular}{|c|c|c|}
\hline \multirow{2}{*}{$\begin{array}{l}\text { Name and Surname } \\
\text { Task }\end{array}$} & \multicolumn{2}{|c|}{ Start date } \\
\hline & Instructions & $\begin{array}{l}\text { Signature of the teacher showing that the } \\
\text { task is completed }\end{array}$ \\
\hline What is the reflection in light? What are the laws of reflection? & Use your coursebook. & \\
\hline $\begin{array}{l}\text { Does the light show particle or wave feature in the } \\
\text { reflection? Explain with figures. }\end{array}$ & Use your coursebook or the internet. & \\
\hline Solve ten questions about the reflection of light. & Use your coursebook or the internet. & \\
\hline $\begin{array}{l}\text { Describe the concepts of total internal reflection and } \\
\text { critical angles with figures. }\end{array}$ & Use your coursebook or the internet. & \\
\hline Explain the working principle of fiber optic cables. & Search on the web. & \\
\hline
\end{tabular}

In this study, we examined the effects of DI on the academic achievements and self-efficacy of students in a physics course who were different in terms of prior knowledge and learning pace. For this purpose, we determined experimental and control groups with a quantitative approach, and then we taught DI in the experimental groups and 5E learning cycle in the control groups. While we were differentiating the instruction in experimental groups, we took students' prior knowledge and learning pace into consideration. Both prior knowledge and pace of learning are variables that teachers who use differentiated teaching in their class take into account frequently (van Geel et al., 2019). We used the agenda strategy for differentiation. As noted, agenda is a strategy when differentiating according to students' prior knowledge (Boerger, 2005). The physics curriculum announced by the national education ministry in Turkey recommends physics teachers to prefer teaching methods and techniques that provide meaningful learning and encourage inquiry and research, including using demonstrations and experiments, animations, and simulations. We used the 5E learning cycle in the control groups because this model arouses the curiosity of students, leads them to research, and enables them to discover knowledge, especially in science education (Bybee et al., 2006). The reason for using the $5 \mathrm{E}$ learning cycle in the control groups is that there is much research in the literature that has concluded that this model is effective in improving students' academic achievement and attitudes in science (Guzel, 2016).

We compared the academic achievements and self-efficacy of the experimental and control groups in this study. The achievement of a student can be defined as the progress of performance in line with educational goals (Verma, 2016). Academic achievement is an important factor in students' professional and personal development. Academic success is in a position that is considered important by teachers, students, parents, and school administrations (Ates, 2016). Some studies have concluded that the $5 \mathrm{E}$ learning cycle affects students' academic achievement positively (Açışlı et al., 2011; Evans, 2004; Wilder and Shuttlewort, 2005). We did not find any study in the literature that compared the effect of the $5 \mathrm{E}$ learning cycle and DI on students' academic achievement.

Since one of the factors that interact with academic achievement is self-efficacy, many researchers have worked on physics self-efficacy (e.g., Kost-Smith et al., 2010). For this reason, another variable in this research was the students' self-efficacy. The concept of self-efficacy, derived from social cognitive theory by Bandura (1977), has been defined as people's belief in their ability to produce the desired effects through their actions. Selfefficacy has emerged as an effective structure that shows that human behavior is affected by people's beliefs. Self-efficacy can also be defined as a dynamic structure that can change with experience and help individuals adapt themselves to complex situations (Bandura and Wood, 1989). Physics self-efficacy can be expressed as students' beliefs about being successful in learning and doing physics (Ajzen, 2002). Self-efficacy has attracted attention by physics education researchers due to its important role in students' success in learning (Kost-Smith et al., 2010). In this study, we compared the change in the self-efficacy of the experimental and control groups after the experimental process.

We sought to investigate the following questions in the study:

1. What is, if any, the significant difference between the academic achievement of the experimental group students (differentiated instruction) and the control group students (5E learning cycle)?

2. What is, if any, the significant difference between the physics self-efficacy of the experimental group students (differentiated instruction) and the control group students (5E learning cycle)?

\section{METHODOLOGY}

\section{Research Design}

For this research, we adopted the quantitative research approach. To find answers to the problems of the research, we used a matching pre-test/post-test control group design (Fraenkel et al., 2012). In this design, the groups of participants were predetermined and it is often not possible to change them. This is a serious limitation, but it is often inevitable (Fraenkel et al., 2012). We preferred this design since it was not possible to randomly assign the students to the groups because it was not possible to change the existing classroom layouts in the schools chosen for the research. In this research, we matched the experiment and control groups with dependent variables. It was the teaching method that was applied independently in the research. Dependent variables were students' academic achievements and physics self-efficacy. We applied pre-test 
and post-test to the experimental and control groups to measure the dependent variables. We present the model of the research in Figure 1.

\section{Participants}

We preferred maximum variation sampling, which contains cases that are purposefully as different from each other as possible (Cohen et al., 2007). For this, we researched three different high schools: A science high school (SHS) where science lessons are taught predominantly, a high school (HS) where science and social contents are distributed equally, and a social science high school (SSHS) where social lessons are taught predominantly. While trying to ensure maximum diversity in school selection, we took into consideration laboratory facilities and teachers' volunteerism. In these schools, we selected an experiment and a control group from the $10^{\text {th }}$ grade (16-year-old students) from each school. We obtained informed consent from all individual participants and parents included in the study. Furthermore, we got legal permission from the Ministry of Education. The research was carried out with the participation of a total of 162 students: 84 students in the experimental groups and 78 students in the control groups. We give the distribution of these students by schools and groups in Table 2. The classes that the teachers who wanted to participate in the research were teaching were assigned as random control and experimental groups. The teachers in each school carried out lessons in both experimental and control groups in their schools. All three teachers involved in the research have over 15 years of professional experience.

\section{Experimental Procedures}

We discussed "Current, Potential Difference, Resistance" and "Electric Circuits" in the "Electricity and Magnetism" unit in the $10^{\text {th }}$-grade physics curriculum in both the control and experimental groups. The learning outcomes of these subjects were as follows:

- Explain the concepts of electric current, resistance, and potential difference.

- Analyze the relationship between current, resistance, and potential difference.

- Explain the reasons for serial and parallel connections of batteries in daily life.

- Explain Kirchhoff's laws.

- Relate electrical energy and electrical power.

In the yearly plan, the prescribed time for this content was $10 \mathrm{~h}$. The experimental procedures lasted for 5 weeks, that is, $2 \mathrm{~h}$ of physics/week. The reason we chose the subject of electricity for this research is that there are studies in the literature about electric current, potential difference, and resistance concepts (Gülçiçek and Kanlı, 2018; Mulhall et al., 2001). In this way, it allowed us to create and select data collection tools while able to compare the results of this research with the previous research.

In both the control and experimental groups, the lessons were taught by the students' physics teachers. One of the researchers also attended the classes as an observer. In control groups, lessons were taught using the $5 \mathrm{E}$ learning cycle. Before the experimental procedure, we explained the $5 \mathrm{E}$ learning cycle to the teachers and offered demonstration lectures on how the method was used in physics teaching. We prepared ten lesson plans, which covered the learning outcomes in the research. We gave these lesson plans to the teachers both in the format of "Microsoft Office-Word 2013" and in the format of "Microsoft Office-PowerPoint 2013" in the digital

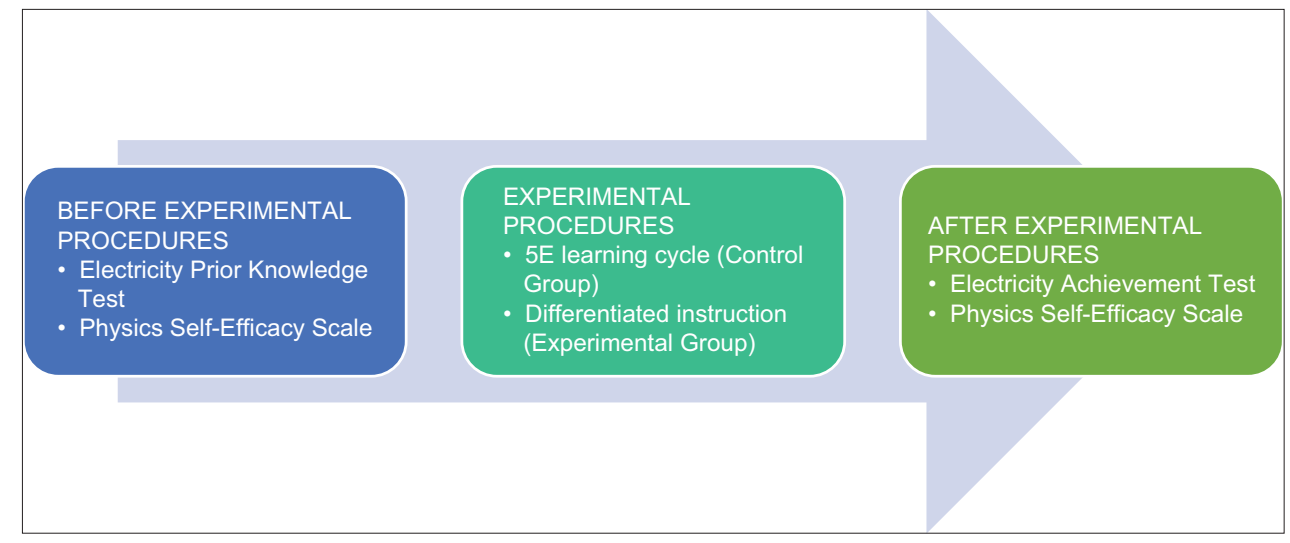

Figure 1: The steps of the research

Table 2: Demographic information of the participants

\begin{tabular}{|c|c|c|c|c|c|c|}
\hline \multirow{2}{*}{$\begin{array}{l}\text { School } \\
\text { Group }\end{array}$} & \multicolumn{2}{|c|}{ SHS } & \multicolumn{2}{|c|}{ HS } & \multicolumn{2}{|c|}{ SSHS } \\
\hline & Experiment & Control & Experiment & Control & Experiment & Control \\
\hline \multicolumn{7}{|c|}{ Number of students } \\
\hline Female & 12 & 14 & 13 & 13 & 16 & 13 \\
\hline Male & 17 & 15 & 15 & 13 & 11 & 10 \\
\hline Total & 29 & 29 & 28 & 26 & 27 & 23 \\
\hline
\end{tabular}


environment. During the lesson, teachers used PowerPoint presentations as guide material with the help of an interactive whiteboard (smartboard).

We used agenda strategy, a differentiated teaching strategy, in the experimental groups. While differentiating the instruction, we took into consideration the students' prior knowledge and learning pace. While we were taking into consideration the prior knowledge of the students, we questioned what they knew on the subject of electricity. For this, we examined $4^{\text {th }}, 5^{\text {th }}$, $6^{\text {th }}, 7^{\text {th }}, 8^{\text {th }}$, and $9^{\text {th }}$-grade physics (science) curriculums with a professor and two physics teachers who were experts in physics education. As a result of this examination, we determined eight learning outcomes that were considered to be related to the $10^{\text {th }}$-grade electricity subject, and which were considered to be a prerequisite for students to learn the learning outcomes in the $10^{\text {th }}$ grade. We present these learning outcomes and grade levels in Table 3.

We administered the "Electricity Prior Knowledge Test" (EPKT) to the students of the experimental group 2 weeks before the study to check the students' prior knowledge. This achievement test, consisting of 24 questions, is aimed at measuring the outcomes given in Table 3 . The test includes three questions related to each of the eight outcomes. We classified students who did not answer one or more of the three questions or incorrectly answered one or more of the three questions as insufficient in prior knowledge. We assumed that if the students answered all three questions about each outcome correctly, they had prior knowledge. In this way, the prior knowledge of the students was examined, and it was revealed which student knew which outcomes and which did not. After that, we prepared an agenda for each student, listing the tasks that should be done individually in the lesson. In these agendas, students had tasks related to the outcomes that the student should learn in the $10^{\text {th }}$ grade, along with tasks to complement the deficiencies of the student's prior knowledge. While preparing the agenda for each student, we

\begin{tabular}{ll}
\hline Table $3:$ Prerequisite learning outcomes \\
\hline Grade & Learning outcomes \\
\hline 4 & $\begin{array}{l}\text { Recognize the circuit elements that make up the simple electric } \\
\text { circuit with their functions and establish a working circuit. }\end{array}$ \\
5 & $\begin{array}{l}\text { Estimate what variables affect lamp brightness in an electrical } \\
\text { circuit and test these estimates. }\end{array}$ \\
5 & $\begin{array}{l}\text { Show the elements of an electrical circuit with their symbols. } \\
\text { Draw an electric circuit diagram, then build and operate that } \\
\text { circuit. }\end{array}$ \\
6 & $\begin{array}{l}\text { Measure the resistance of a conductor and specify its unit. } \\
\text { Explore what serial and parallel connection is and draw a } \\
\text { circuit diagram consisting of both serial and parallel connected } \\
\text { bulbs. } \\
\text { Connect the ammeter to the circuit in series and name the value } \\
\text { it reads as current and express its unit. } \\
\text { Connect the voltmeter parallel to the circuit and measure the } \\
\text { voltage (potential difference) between two points and express } \\
\text { its unit. }\end{array}$ \\
7 &
\end{tabular}

created a standard task list with 33 tasks. Thirteen of these tasks were related to prior knowledge and 20 of them were aimed at teaching $10^{\text {th }}$-grade outcomes. The first 13 tasks differed according to the deficiencies of the student's prior knowledge. These 13 tasks were aimed at teaching the outcomes given in Table 3, and the tasks that the student lacks were included in their agendas. After completing these tasks, the student would start 20 tasks aimed at teaching $10^{\text {th }}$-grade outcomes. These 20 tasks were aimed at teaching the outcomes in the $10^{\text {th }}$-grade curriculum mentioned above. Therefore, a student's agenda had at least 20 and a maximum of 33 tasks. Thus, the course was differentiated according to the students' prior knowledge. The students performed the tasks on the agenda individually, sometimes carrying out experimental tasks in groups of two or three. The course was differentiated according to the learning speed of the students as the time for completing the task was completely dependent on the student.

\section{Data Collection Tools}

\section{Electricity prior knowledge test (EPKT)}

While preparing the EPKT, we considered the outcomes in Table 3. We created a question pool that had 63 multiple-choice questions with five options to measure these outcomes. Two physics teachers examined the questions and they reduced the number of questions to 32 . The distribution of these 32 questions by outcomes was such that there would be four questions for each outcome out of the eight achievements given in Table 3. The test was administered to the 162 participating $10^{\text {th }}$-grade students. We coded the answers by giving 1 point for correct answers and 0 points for wrong and blank answers to students. We performed item analysis on the data obtained after this coding process. As a result of item analysis, we created a test consisting of 24 items. In this selection process, we took into consideration the item difficulty index, item discrimination index, and the outcome related to the question. While the EPKT took its final form consisting of 24 items, the test included three items for each outcome out of the eight outcomes given in Table 3. We administrated EPKT to $24910^{\text {th }}$ grade students who did not participate in the research in the same schools for the reliability analysis of the test, which consisted of 24 questions. We calculated the average difficulty index and the average discrimination index of the test by making item analysis again on the data obtained. The average difficulty of the test was 0.56 and the average discrimination was 0.43 . Based on these statistics, it can be said that the test has average difficulty and good discrimination. We calculated the KR-20 coefficient, one of the methods based on a single application, to determine the reliability coefficient of the test. As a result of the calculation, the KR-20 coefficient was found to be 0.83 .

\section{Electricity achievement test (EAT)}

With the EAT, we aimed to measure the outcomes in the subjects of "Current, Potential Difference, Resistance" and "Electric Circuits" within the $10^{\text {th }}$ Grade Physics Curriculum. For this purpose, we examined the $10^{\text {th }}$-grade coursebook and workbook and created a question pool consisting of 
46 questions. Three experts with an associate professor title in the field of physics education and two physics teachers examined the questions, and the number of questions was reduced to 32. All of the questions were multiple-choice and had five options. We asked these questions to $11^{\text {th }}$ and $12^{\text {th }}$ grade students who had learned these subjects previously. A total of 115 students participated in this pilot application. We allowed $45 \mathrm{~min}$ for the students to complete the test. When choosing the item to be included in the final test, we took attention that the item was not too difficult or too simple and that the discrimination index was greater than 0.20 . We created a test consisting of 18 items because of the item analysis. For the reliability study of EAT containing 18 items, the test was applied to $25111^{\text {th }}$ grade students. We did item analysis again using the data collected and calculated the average difficulty index of the test as 0.50 and the discrimination index as 0.52 . It can be argued that the test had an average difficulty level and good discrimination power. As a result of the calculations, we found 0.81 the KR-20 reliability coefficient of the test.

\section{Physics self-efficacy scale (PSES)}

We used the PSES to compare the physics self-efficacy beliefs of the control and experimental group students before and after the courses. PSES was developed by Maskan (2010) to measure the change in the self-efficacy levels of undergraduate students against physics, and we obtained permission by e-mail from the author for use in this research. The scale consists of 11 items. The scale is a five-point Likert-type scale and coded as "Always (5)," "Mostly (4)," "Sometimes (3)," "Rarely (2)," and "Never (1)." For positive propositions, this coding is also applied as scoring, while negative propositions are written and scored 1 instead of 5, 2 instead of 4. Six of the items in the scale are positive and five of them are negative. The higher the total score obtained after scoring the items, the higher the student's self-efficacy in physics.

University students were chosen as the sample when developing the PSES. In this research, the sample was high school $10^{\text {th }}$-grade students. For this reason, we applied the scale before the research to 121 students who had similar characteristics to the sample. We found the Cronbach's $\alpha$ reliability coefficient 0.90 of the data obtained because of this application. Besides, we interviewed two students individually and concluded that the students were at a level where they could understand the questions.

\section{Data Collection}

We carried out the research physics courses in the participating students' schedules in schools. We administered the EPKT and PSES to the control and experimental groups 2 weeks before the application as a pre-test. The EAT and PSES as a post-test in the physics lesson in the week after the applications ended to examine the effects of the applications.

\section{Data Analysis}

We used SPSS version 20 package program in the analysis of the collected quantitative data. We checked first whether the quantitative data collected in the analysis process of the data met the assumptions of parametric tests. Parametric hypothesis testing assumptions are as follows (Field, 2009):

- The data should show a normal distribution.

- Variances must be homogeneous.

- The data should be interval or ratio.

- The answers given by the groups should be independent from each other.

To take advantage of the parametric hypothesis tests, it is necessary to determine whether the data obtained has a normal distribution. We examined the Shapiro-Wilk normality test, measures of central tendency, skewness, and kurtosis coefficient values to determine whether the data fit the normal distribution (Field, 2009). We did the Levene test for EPKT, EAT, and PSES to determine whether the variances of the data obtained from the control and experimental groups were equal. We determined that the data obtained from the data collection tools showed the normal distribution and their variances were equal. In this research, since each measurement was obtained from only one student, it can be said that in all tests performed, the condition of the answers given by the groups was independent. We decided to use parametric tests in the analysis of the data obtained. In this context, we used the following tests:

1. We used independent samples t-test to determine whether there was a difference between the students in the control and experimental groups before the courses about electricity.

2. We used analysis of covariance (ANCOVA) to determine whether there was a significant difference between the success of the students in the control and experimental groups after the experimental procedure. ANCOVA is another type of variance analysis. While examining the effect of the independent variable on the dependent variable, it is performed by controlling another continuous variable that is likely to affect the dependent variable and measured before the dependent variable (Field, 2009). While we were comparing the EAT results of the control and experimental groups, we selected the EPKT averages as the covariate.

3. We used the two-factor mixed-measures ANOVA to test whether the pre-test and post-test scores of the experimental and control groups collected with PSES differed.

\section{Findings}

\section{Findings from electricity prior knowledge test}

We investigated whether there was a difference in students' prior knowledge about electricity between the experimental and control groups in schools before the courses. For this purpose, we conducted an independent samples t-test and present the results in Table 4. According to Table 4, no significant difference was found between the students in the experimental and control groups in the three schools (SHS: $\mathrm{t}_{(56)}=.437$, HS: $\mathrm{t}_{(51)}=.151$, SSHS: $\left.\mathrm{t}_{(48)}=.172 ; \rho>.05\right)$. According to these findings, it can be said that the electricity prior knowledge of the groups in schools was similar in the experiment and control groups in each school. 


\section{Findings from electricity achievement test}

We conducted an analysis of covariance to determine whether there was a difference between the academic achievement of students in the experimental and control groups. We compared experimental and control groups in each school among themselves. We used the averages of the EPKT as the control variable. We present mean and adjusted mean values of students' EAT scores in Table 5.

We provide the ANCOVA results in Table 6. There was no significant difference between the scores of the experimental

\begin{tabular}{llcccccc}
\hline \multicolumn{7}{l}{ Table 4: Independent samples t-test results } \\
\hline School & Group & $\mathbf{N}$ & $\overline{\mathbf{X}}$ & SD & $\mathbf{d f}$ & $\mathbf{t}$ & $\boldsymbol{\rho}$ \\
\hline SHS & Experimental & 29 & 13.45 & 3.69 & 56 & 0.783 & 0.437 \\
& Control & 29 & 12.76 & 2.97 & & & \\
HS & Experimental & 28 & 10.00 & 2.76 & 51 & -1.458 & 0.151 \\
& Control & 28 & 11.08 & 2.61 & & & \\
\multirow{2}{*}{ SSHS } & Experimental & 27 & 10.56 & 3.00 & 48 & -1.387 & 0.172 \\
& Control & 23 & 11.78 & 3.24 & & & \\
\hline
\end{tabular}

Table 5: Mean and adjusted mean values for EAT scores

\begin{tabular}{llccc}
\hline School & Group & N & $\overline{\mathbf{X}}$ & Adjusted mean \\
\hline SHS & Experimental & 29 & 12.34 & 12.25 \\
& Control & 29 & 11.90 & 11.98 \\
\multirow{3}{*}{ HS } & Experimental & 28 & 9.18 & 8.94 \\
& Control & 28 & 5.96 & 5.98 \\
\multirow{2}{*}{ SSHS } & Experimental & 27 & 8.04 & 8.05 \\
& Control & 23 & 6.93 & 6.92 \\
\hline
\end{tabular}

group and the control group students at the SHS school from the EAT $\left(\mathrm{F}_{(1,55)}=.131 ; \rho>.05 ; \eta 2=.002\right)$. Although the adjusted mean of the experimental group was higher than that of the control group, this difference was not significant. There was a significant difference between the EAT scores of the experimental and the control group students at the HS school $\left(F_{(1,50)}=24.369 ; \rho<.01 ; \eta 2=.328\right)$. The adjusted mean of the experimental group was higher than that of the control group and this difference was significant. Students in lessons taught with differentiated instruction at the HS school were more successful than students in lessons taught according to the $5 \mathrm{E}$ learning cycle. There was a significant difference between the experimental group and control group students at the SSHS $\operatorname{school}\left(\mathrm{F}_{(1,47)}=4.585 ; \rho<.05 ; \eta 2=.089\right)$.

\section{Findings from physics self-efficacy scale}

We present the two-factor mixed-measures ANOVA results to compare the data collected with PSES in Table 7. There was no significant difference between the experimental group and the control group at SHS school $\left(\mathrm{F}_{(1,56)}=2.851 ; \rho>0.05\right)$. For the group-measurement common effect, there was no significant difference between the experimental group and the control group at HS school $\left(\mathrm{F}_{(1,52)}=2.346 ; \rho>0.05\right)$. In the SSHS school, there was no significant difference between the experimental group and the control group for the groupmeasurement common effect $\left(\mathrm{F}_{(1,48)}=1.418 ; \rho>0.05\right)$. According to these findings, as a result of the experimental procedure, there was no difference between the physics selfefficacy beliefs of the experimental group students and the control group students.

\section{Table 6: ANCOVA results}

\begin{tabular}{|c|c|c|c|c|c|c|c|}
\hline School & Source & Sum of squares & $d f$ & Mean Square & $\mathbf{F}$ & $\rho$ & $\eta^{2}$ \\
\hline \multirow[t]{7}{*}{ SHS } & Corrected Model & 48.103 & 2 & 24.052 & 3.164 & 0.050 & 0.103 \\
\hline & Intercept & 256.161 & 1 & 256.161 & 33.701 & 0.000 & 0.380 \\
\hline & EPKT & 45.189 & 1 & 45.189 & 5.945 & 0.018 & 0.098 \\
\hline & Group & 0.997 & 1 & 0.997 & 0.131 & 0.719 & 0.002 \\
\hline & Error & 418.052 & 5 & 7.601 & & & \\
\hline & Total & 8987.000 & 8 & & & & \\
\hline & Corrected Total & 466.155 & 57 & & & & \\
\hline \multirow[t]{7}{*}{ HS } & Corrected Model & 119.982 & 2 & 59.991 & 13.205 & 0.000 & 0.346 \\
\hline & Intercept & 197.655 & 1 & 197.655 & 43.508 & 0.000 & 0.465 \\
\hline & EPKT & 0.774 & 1 & 0.774 & 0.170 & 0.682 & 0.003 \\
\hline & Group & 110.708 & 1 & 110.708 & 24.369 & 0.000 & 0.328 \\
\hline & Error & 227.150 & 50 & 4.543 & & & \\
\hline & Total & 3366.000 & 53 & & & & \\
\hline & Corrected Total & 347.132 & 52 & & & & \\
\hline \multirow[t]{7}{*}{ SSHS } & Corrected Model & 15.527 & 2 & 7.763 & 2.357 & 0.106 & 0.091 \\
\hline & Intercept & 198.201 & 1 & 198.201 & 60.180 & 0.000 & 0.561 \\
\hline & EPKT & 0.015 & 1 & 0.015 & 0.005 & 0.946 & 0.000 \\
\hline & Group & 15.102 & 1 & 15.102 & 4.585 & 0.037 & 0.089 \\
\hline & Error & 154.793 & 47 & 3.293 & & & \\
\hline & Total & 2938.000 & 50 & & & & \\
\hline & Corrected Total & 170.320 & 49 & & & & \\
\hline
\end{tabular}




\begin{tabular}{|c|c|c|c|c|c|c|c|}
\hline School & Source & Sum of squares & df & Mean Square & $\mathbf{F}$ & $\rho$ & $\eta^{2}$ \\
\hline \multirow[t]{8}{*}{ SHS } & Between subject & 12.105 & 57 & & & & \\
\hline & Group & 0.031 & 1 & 0.031 & 0.146 & 0.704 & 0.003 \\
\hline & Error & 12.074 & 56 & 0.216 & & & \\
\hline & Within subject & 3.549 & 58 & & & & \\
\hline & Measurement & 0.301 & 1 & 0.301 & 5.453 & 0.023 & 0.089 \\
\hline & Group* Measurement & 0.157 & 1 & 0.157 & 2.851 & 0.097 & 0.048 \\
\hline & Error (Measurement) & 3.091 & 56 & 0.055 & & & \\
\hline & Total & 15.654 & 115 & & & & \\
\hline \multirow[t]{8}{*}{ HS } & Between subject & 8.029 & 53 & & & & \\
\hline & Group & 0.222 & 1 & 0.222 & 1.478 & 0.230 & 0.028 \\
\hline & Error & 7.807 & 52 & 0.150 & & & \\
\hline & Within subject & 4.459 & 54 & & & & \\
\hline & Measurement & 0.003 & 1 & 0.003 & 0.033 & 0.857 & 0.001 \\
\hline & Group* Measurement & 0.192 & 1 & 0.192 & 2.346 & 0.132 & 0.043 \\
\hline & Error (Measurement) & 4.264 & 52 & 0.082 & & & \\
\hline & Total & 12.488 & 107 & & & & \\
\hline \multirow[t]{8}{*}{ SSHS } & Between subject & 6.873 & 49 & & & & \\
\hline & Group & 0.136 & 1 & 0.136 & 0.971 & 0.329 & 0.020 \\
\hline & Error & 6.737 & 48 & 0.140 & & & \\
\hline & Within subject & 3.644 & 50 & & & & \\
\hline & Measurement & 0.102 & 1 & 0.102 & 1.418 & 0.240 & 0.029 \\
\hline & Group* Measurement & 0.102 & 1 & 0.102 & 1.418 & 0.240 & 0.029 \\
\hline & Error (Measurement) & 3.440 & 48 & 0.072 & & & \\
\hline & Total & 10.517 & 99 & & & & \\
\hline
\end{tabular}

We created a column chart related to the pre-test and post-test scores of the groups, Figure 2. Looking at Figure 2, it can be seen that the post-test scores of all experimental groups were higher than the pre-test scores. When the self-efficacy beliefs of the control groups were analyzed, it was seen that there was only an increase in the SHS school, a decrease in the HS school, and no change in the SSHS school.

\section{DISCUSSION AND CONCLUSION}

In this research, we investigated the effect of using DI in physics lessons on students' academic achievement and physics self-efficacy. The research was carried out in three different schools with three experiment and control groups. The effects of DI on academic success have given different results according to schools. There was no significant difference between experimental and control groups in the SHS school. We can interpret this result as "Teaching according to differentiated instruction and the 5E learning cycle affect students' academic achievement in the same way." On the other hand, in the HS school and the SSHS school, there was a significant difference in the experimental and control groups in favor of the experimental group. We can interpret this result as "Differentiated instruction increases students' academic achievement more than the 5E model." Although the two interpretations given here are seen to be contradictory, it will be understood that both interpretations are acceptable when looking at similar studies in the literature. In some studies investigating the effect of DI on academic

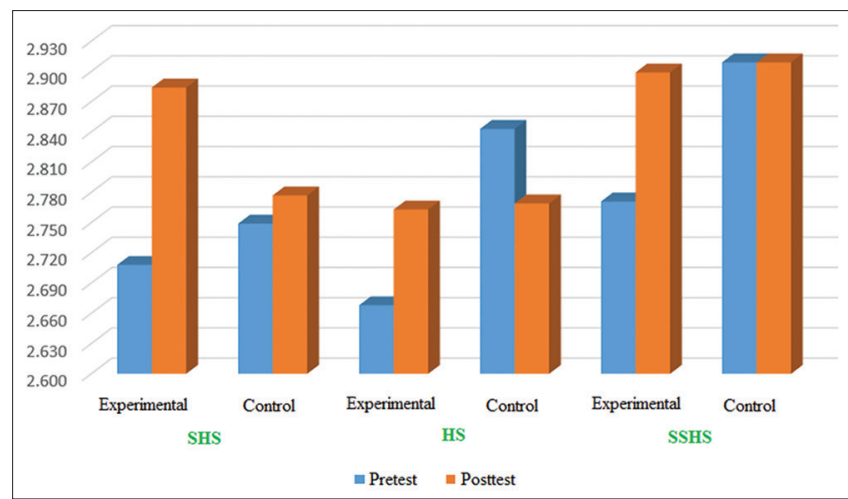

Figure 2: The column chart of pre-test/post-test scores of PSES

achievement claimed that DI does not affect the achievement (Burns, 2005; Ducey, 2011; Maxey, 2013; Tulbure, 2013; Vincent, 2012), but in some studies, it has been argued that DI increases academic achievement more (Baumgartner et al., 2003; Chamberlin and Powers, 2010; Gilbert, 2011). Prast et al. (2018) suggested that students with low, medium, and high achievement levels benefit from DI and that DI should be used at all student levels. Richards and Omdal (2007) investigated the effect of DI on the academic achievements of high school students on astronomy in physics according to differentiating students' prior knowledge. The research, which included 388 students and seven control and experimental groups, took 4 weeks. As a result of their research, they concluded that low and medium achievement levels benefitted more from 
differentiated education and their academic success increased more. In students with high achievement level, there was no significant difference in terms of academic success in the experimental and control groups. It can be said that this result fits with the result revealed in terms of academic achievement in this research. Because when we look at the average scores obtained from EAT from the students in the SHS school, it can easily be said that they are more successful than HS and SSHS students. It is also a fact that students in the SHS school have a more positive attitude toward physics because it is a science high school. Based on these results, it can be said that DI improves the academic achievement of low and medium level students. While comparing the experimental and control groups here it should not be overlooked that the lessons are conducted according to the 5E learning cycle in the control group, because many studies have concluded that the $5 \mathrm{E}$ learning cycle increases students' academic achievement more than teacher-centered education (Lord, 1999; Odom and Kelly, 2001; Saka and Akdeniz, 2006).

Both before and after the experimental procedures, we applied the PSES to students in the experimental and control groups. While analyzing the data obtained from the scale, we used two-factor mixed-measures ANOVA. There was no significant difference between the experimental group and the control group in all three schools. This result can be interpreted as that students' physics self-efficacy is similarly affected by both teaching methods. In parallel with this result, Kocakaya (2008) formed eight groups with 167 students in his study, which aimed to examine the factors affecting student success and the relationships between these factors. Four of the groups were taught using computer-assisted cooperative learning, and four were taught using the computer-assisted $7 \mathrm{E}$ model. As a result of his research, he claimed that practices based on the constructivist approach did not affect students' self-efficacy. On the other hand, some studies argue that differentiated teaching in the literature increases students' self-efficacy. In his study, Hood (2012) investigated the effect of differentiated teaching on students' mathematics achievements and self-efficacy beliefs. In his experimental research with the $1^{\text {st }}$-year students of the university, he worked with three experiments and a control group. He argued that DI developed students' self-efficacy.

\section{Implications}

According to the results of the research, the effect of DI on academic achievement is related to the level of the students. Researchers or teachers who want to use DI in the teaching environment should consider the level of their students. Level groups can be established in the classroom. If the academic achievements of students are close to each other and all of them are high achievers, it may be suggested that the activities in the course are above the program level.

The results of the research show that DI can be preferred in low and middle level students instead of the $5 \mathrm{E}$ learning cycle in physics lessons. DI can be suggested according to the prior knowledge of low and medium level students.
In this research on $10^{\text {th }}$-grade electricity, the average correct answers of the students in the 24-question prior knowledge test ranged between 10 and 13, according to the schools. The numbers of correct answers given by students to the fourth, fifth, sixth, and seventh grade questions were low. Teachers may be advised to examine the prior knowledge on the subject and correct the deficiencies before starting electricity concepts in the tenth grade.

In this study, differentiation was made according to the prior knowledge and learning pace of students. In addition to these differences, researchers could differentiate according to students' learning styles and interests.

In this research, while creating an agenda, secondary, and high school curriculums were discussed. There may also be students who can overcome these curriculums in the teaching environment. Researchers can add tasks above the high school program to students' tasks, taking into account the different profiles of students in the class.

The curriculum must be flexible for the DI to work fully and for teachers to implement it properly. This flexibility can be provided in new curriculums.

\section{ACKNOWLEDGMENTS}

This article was produced from the doctoral dissertation of Riza Salar, conducted under the supervision of Umit Turgut.

\section{REFERENCES}

Açışl1, S., Yalçın, S.A., \& Turgut, Ü. (2011). Effects of the 5E learning model on students' academic achievements in movement and force issues. Procedia - Social and Behavioral Sciences, 15, 2459-2462.

Ajzen, I. (2002). Perceived behavioral control, self-efficacy, locus of control, and the theory of planned behavior. Journal of Applied Social Psychology, 32(4), 665-683.

Ates, B. (2016). Psychological well-being and social competence as a predictor of academic success of university students. Electronic Journal of Social Sciences, 15(59), 1203-1214.

Bafile, C. (2010). Different Strokes for Little Folks: Carol Ann Tomlinson on Differentiated Instruction. Available from: http://www.educationworld. com/a issues/chat/chat107.shtml.

Bandura, A. (1977). Self-efficacy: Toward a unifying theory of behavioral change. Psychological Review, 84(2), 191-215.

Bandura, A., \& Wood, R.E. (1989). Effect of perceived controllability and performance standards on self-regulation of complex decision making. Journal of Personality and Social Psychology, 56(5), 805-814.

Baumgartner, T., Lipowski, M.B., \& Rush, C. (2003). Increasing Reading Achievement of Primary and Middle School Students through Differentiated Instruction. Available from: https://www.eric. ed.gov/?id=ED479203.

Blaz, D.D. (2006). Differentiated Instruction: A Guide for Foreign Language Teachers. London: Routledge.

Boerger, M.V. (2005). Differentiated Instruction in the Middle School Math Classroom: A Case Study (Master Dissertation). Tacoma: Pacific Lutheran University, ProQuest Dissertations and Theses.

Boushey, G., \& Moser, J. (2006). The Daily Five: Fostering Literacy Independence in Early Grades. Portland: Stenhouse Publishers.

Burns, J.P. (2005). An Analysis of the Implementation of Differentiated Instruction in a Middle School and High School and the Effects of Implementation on Curriculum Content and Student Achievement (Doctoral Dissertation). South Orange, NJ: Seton Hall University.

Bybee, R.W., Taylor, J.A., Gardner, A., Van Scotter, P., Powell, J.C., 
Westbrook, A., \& Landes, N. (2006). The BSCS 5E Instructional Model: Origins, Effectiveness, and Applications. Available from: https://www.researchgate.net/publication/242363914 The BSCS 5E Instructional_Model_Origins_Effectiveness_and_Applications.

Chamberlin, M., \& Powers, R. (2010). The promise of differentiated instruction for enhancing the mathematical understandings of college students. Teaching Mathematics and Its Applications, 29(3), 113-139.

Cohen, L., Manion, L., \& Morrison, K. (2007). Research Methods in Education. $6^{\text {th }}$ ed. London: Routledge.

Cusumano, C., \& Mueller, J. (2007). How differentiated instruction helps struggling students. Leadership, 36(4), 8-10.

Ducey, M.N. (2011). Improving Secondary Science Achievement through the Implementation of Differentiated Instruction (Doctoral Dissertation). Memphis, Tennessee: The University of Memphis, ProQuest Dissertations and Theses.

Evans, C. (2004). Learning with inquiring minds. The Science Teacher, $71(1), 27-30$.

Field, A. (2009). Discovering Statistics using SPSS. New York: Sage Publications.

Fischer, K.W., \& Rose, L.T. (2001). Webs of skill: How students learn. Educational Leadership, 59(3), 6-12.

Fraenkel, J.R., Wallen, N.E., \& Hyun, H.H. (2012). How to Design and Evaluate Research in Education. $8^{\text {th }}$ ed. New York: McGraw-Hill Companies.

George, P. (2005). A rationale for differentiating instruction in the regular classroom. Theory into Practice, 44(3), 185-193.

Gilbert, D. (2011). Effects of Differentiated Instruction on Student Achievement in Reading (Doctoral Dissertation). Minneapolis, Minnesota: Walden University, ProQuest Dissertations and Theses.

Gülçiçek, Ç., \& Kanli, U. (2018). Pre-service physics teachers' recognition of apparatuses used in mechanics and electricity and magnetism experiments. Universal Journal of Educational Research, 6(12), 28642874.

Guzel, H. (2016). The effect of brightness of lamps teaching based on the 5E model on students' academic achievement and attitudes. Educational Research and Reviews, 11(17), 1670-1678.

Hall, T. (2002). Differentiated Instruction. Available from: https://www.drhatfield.com/educ342/Differentiated Instruction.pdf.

Hall, T., Strangman, N., \& Meyer, A. (2003). Differentiated Instruction and Implications for UDL Implementation. Available from: https://sde. ok.gov/sites/ok.gov.sde/files/DI_UDL.pdf.

Hood, O.D., Jr. (2012). Differentiated Instruction in Developmental Mathematics Classes and Achievement of Ethnic Minority Students (Doctoral Dissertation). Ann Arbor, MI: ProQuest Dissertations and Theses.

Kocakaya, S. (2008). Investigation of Relations among the Factors that Affect Physics Course Achievement of High School Students using Path Analysis Technique (Doctoral Dissertation). Diyarbakır, Turkey: Dicle University.

Kost-Smith, L.E., Pollock, S.J., \& Finkelstein, N.D. (2010). Gender disparities in second-semester college physics: The incremental effects of a "smog of bias". Physical Review Special Topics-Physics Education Research, 6(2), 1-17.

Larsen, K. (2004). Sink or swim. Library Media Connection, 23(3), 14-16.

Lawrence-Brown, D. (2004). Differentiated instruction: Inclusive strategies for standards-based learning that benefit the whole class. American Secondary Education, 32(3), 34-62.

Levy, H.M. (2008). Meeting the needs of all students through differentiated instruction: Helping every child reach and exceed standards. The Clearing House, 81(4), 161-164.

Lord, T. (1999). A comparison between traditional and constructivist teaching in environmental science. The Journal of Environmental Education, 30(3), 22-28.

Maskan, A. (2010). An evaluation of prospective physics and maths teachers' self-efficacy beliefs toward physics. Journal of Uludag University Faculty of Education, 23(1), 31-42.

Maxey, K.S. (2013). Differentiated Instruction: Effects on Primary Students' Mathematics Achievement (Doctoral Dissertation). Ann Arbor, MI:
ProQuest Dissertations and Theses.

Mulhall, P., McKittrick, B., \& Gunstone, R. (2001). A perspective on the resolution of confusions in the teaching of electricity. Research in Science Education, 31(4), 575-587.

Odom, A.L., \& Kelly, P.V. (2001). Integrating concept mapping and the learning cycle to teach diffusion and osmosis concepts to high school biology students. Science Education, 85(6), 615-635.

Pinnell, G.S., \& Fountas, I. (2007). The Continuum of Literacy Learning, Grades K-2: A Guide to Teaching. United States: Heinemann.

Prast, E.J., Van de Weijer-Bergsma, E., Kroesbergen, E.H., \& Van Luit, J.E. (2018). Differentiated instruction in primary mathematics: Effects of teacher professional development on student achievement. Learning and Instruction, 54, 22-34.

Reis, S.M., Kaplan, S.N., Tomlinson, C.A., Westberg, C.K.L., Callahan, C.M., \& Cooper, C.R. (1998). How the brain learns. Educational Leadership, 56(3), 74-77.

Richards, M.R.E., \& Omdal, S.N. (2007). Effects of tiered instruction on academic performance in a secondary science course. Journal of Advanced Academics, 18(3), 424-453.

Roberts-Mahon, V. (2016). A Case Study on Differentiated Instruction in an Elementary School Classroom (Doctoral Dissertation). Ann Arbor, MI: ProQuest Dissertations and Theses.

Saka, A., \& Akdeniz, A.R. (2006). The development of computer based material about genetic and application according to 5E model. Turkish Online Journal of Educational Technology, 5(1), 129-141.

Salar, R., \& Turgut, Ü. (2015). Implementing differentiated instruction on pre-service physics teachers. Bartin University Journal of Faculty of Education, 4(2), 682-695.

Sternberg, R.J., \& Zhang, L. (2005). Styles of thinking as a basis of differentiated instruction. Theory Into Practice, 44(3), 245-253.

Subban, P. (2006). Differentiated instruction: A research basis. International Educational Journal, 7(7), 935-47.

Tomlinson, C.A. (1999). The Differentiated Classroom. Responding to the Needs of All Learners. Alexandria: Association for Supervision and Curriculum Development.

Tomlinson, C.A. (2001). How to Differentiate Instruction in Mixed Ability Classrooms. $2^{\text {nd }}$ ed. Alexandria: Association for Supervision and Curriculum Development.

Tomlinson, C.A. (2003). Fulfilling the Promise of the Differentiated Classroom: Strategies and Tools for Responsive Teaching. Alexandria: Association for Supervision and Curriculum Development.

Tomlinson, C.A. (2009). Learning profiles and achievement. School Administrator, 66(2), 28-29.

Tulbure, C. (2013). The effects of differentiated approach in higher education: An experimental investigation. Procedia-Social and Behavioral Sciences, 76, 832-836.

Van Geel, M., Keuning, T., Frèrejean, J., Dolmans, D., van Merriënboer, J., \& Visscher, A.J. (2019). Capturing the complexity of differentiated instruction. School Effectiveness and School Improvement, 30(1), 51-67.

Van Tassel-Baska, J., \& Stambaugh, T. (2005). Challenges and possibilities for serving gifted learners in the regular classroom. Theory into Practice, 44(3), 211-217.

Verma, A.N.J.U. (2016). A study of academic achievement among high school students in relation to their study habits. International Journal of Research in Humanities, Arts and Literature, 4(3), 75-88.

Vincent, C. (2012). Effects of Implementing Differentiated Instruction on Learners' Reading Achievement (Doctoral Dissertation). Ann Arbor, MI: ProQuest Dissertations and Theses.

Wilder, M., \& Shuttleworth, P. (2005). Cell inquiry: A 5E learning cycle lesson. Science Activities: Classroom Projects and Curriculum Ideas, 41(4), 37-43.

Willis, S., \& Mann, L. (2000). Differentiating instruction: Finding manageable ways to meet individual needs. Curriculum Update, 4, 1-3.

Wormeli, R. (2007). Differentiation: From Planning to Practice, Grades 6-12. Portland: Stenhouse Publishers. 